\title{
Funerals, Families, and Family Nursing: Lessons of Love and Practice
}

As this issue of the Journal of Family Nursing is being readied for publication, I am finding myself drawn to thinking about being in a practice profession that says something about our lives. As family nurses, we are passionate about families our practices, our writing, our teaching, and our discussions with equally passionate (and even our less converted) colleagues. Yet, at the heart of this passion lies the simple and wonderful reality that we also live in families; we are families. We suffer the local, heartfelt, and life-changing complexities that characterize our own particular families.

I am compelled to look to these local realities. This week, during a time when this journal's editor, Dr. Janice Bell, is intimately and passionately involved in the care of her own critically ill mother, I stood at the funeral of Dr. Lorraine Wright's mother, Hazel Wright. I heard stories of her life and her recent courageous and noble journey with the profoundly debilitating illness of multiple sclerosis. More than these stories, I heard stories of Mrs. Wright as a daughter, a sister, a wife, a mother, a mother-in-law, an aunt, a grandmother, a friend, and an employer. I was struck with this family's words of tribute and love, care and passion, and gratitude and humor. Yet, I must admit that I was even more struck with the row of women sitting together alone in a pew in the chapel. There were six of them, different ages, sizes, colors, and clothes. They came from different families. None were related to the Wright family. Yet, what they seemed to have in common were their shared tears for Mrs. Wright. I did not know who they were, hut I knew that they had loved her. I found out later that they were Mrs. Wright's personal caregivers, and that they sat together as honorary pallbearers. They were with her 24 hours a day; they bathed her, dressed her, changed her position in bed, cleansed her, and fed her. They did not, however, simply care for her physical body they also tended her spirit, gently, respectfully, and knowingly. They came to love her. These women hugged and kissed Mrs. Wright. In addition, they did something else -- they came to love her family. I watched the humble, almost shy way in which they continued, even after the service, to watch out for Mrs. Wright's husband amid her children. I heard the story of how Mary came back the day after Mrs. Wright died to make Mr. Wright's bed, do his laundry, and help him put on his socks, and I realized that I was looking at family nursing. These caregivers are not nurses, but they know how to nurse.

This experience of meeting these women has invited some rather humbling reflections. It is interesting to me how we, as nurses, are quite passionate about defining ourselves. One motivation may be that nursing has struggled with attempts to professionalize the discipline, to emancipate it from the auspices of medicine, and to distinguish it from the umbrella of other human sciences such as sociology, social work, or psychology. Family nursing itself has struggled with issues of definition, distinction, and clarifications between specialist and generalist practices it occurs to me that sometimes, in this ontological pursuit, we become more enamoured with the noun of nursing than with the verb. I suggest that nursing, as a noun, only truly finds itself in the verb, in the action of nursing. The verb nurse is defined as the action of nursing, 
caring, harboring, sustaining, and supporting (Hoad, 1986: Neufeldt \& Guralnik, 1988). As I watched and heard stories of these wonderful women, these personal caregivers, it occurred to me that we do not get to own that verb, and that is perhaps why, in our pursuits to define ourselves and our profession, we become at times rather zealous in own the noun. Perhaps in this endeavor of turning our attention to the noun, we have lost the focus on our action on the verb of nursing. Perhaps our concern for distinguishing might be related to the current issues of downsizing, economics, deskilling of nurses, individual licensure, or collaborative trends. Perhaps it is related to pride. However, despite whatever drives us to define and distinguish, I believe that the ultimate question we need to ask ourselves is if it is steering us away from valuing the action. Toulmin (1972) offered a wondering of when intellectual activity takes on the character of a discipline, and I suggest that the character of a discipline is found in the context of action and practice. We become family nurses, not simply in our definitions of ourselves but in the praxis of how we live our beliefs, our philosophies, our theories and knowledge, our values, and our experiences.

The definition of practice is the exercise or action of a profession. It is more than a place. If a lawyer describes her practice of law, it is not a building that houses her office and where she hangs her shingle, it is how she lives out her profession, education, learning, and specialized knowledge. It is how her knowledge comes to the action of doing something. Practice is how we live out our discipline: it is the life of the discipline. Similarly, in nursing, it is in action and the relief of suffering that all of our research, education, knowledge, skill, and intuition meet in a place that matters, in a place that defines what it is that we do to be important. Practice does not solely mean direct nursing care, because educators practice nursing in the domain of education and researchers practice nursing in the domain of research. All of these acts of nursing are what gives an identity to our practice. Bishop and Scudder (1995) suggested that, before nursing fell under the seduction of science, it did define and describe itself as a practice. The ancient healing traditions of women set the foundation that nursing also contains a value or moral imperative to not only care for the ill but also to foster health. Contained in this foundation and tradition, there has always been a thread of practical wisdom in nursing.

Gadamer (1989) suggested that science and knowledge are kinds of technology. Technology is an application of a particular knowledge and way of thinking in the world with the intent to control or intervene. Although the intent might be directed toward creating good, technology itself is neutral. Practice, however, is not neutral; it is integrally involved and morally invested in its aims. It is a living, breathing, generative, and acting thing. Borgmann (1992) suggested that, as in German tradition, the word practical is synonymous with moral, and therefore, our practice and the decisions that govern our practice and our conduct within it are moral decisions. Practice involves us morally, practically, and spiritually.

Bishop and Scudder (1995) suggested that practice fosters good in the world: "Nursing fosters the physical and psychological well-being of persons the adequacy of a practice is judged by how well it achieves the good at which it 
aims" (p. 266). Therefore, what should be important in articulating and defining a discipline is not in claiming its philosophy and theories but in emphasizing how its practices are both constituted and improved. There are lessons to be learned from Mrs. Wright's caregivers in how they practice

I do not, however, mean to imply that I value practice over theory. I am equally affronted by the accusation that, because now as a doctoral student paying more attention to theory, I cannot practice as well as those practitioners who are not as immersed in theory. This accusation rings with the implication that I have somehow forgotten my roots. I would argue this allegation with the belief that theory informed practice is as important as practice informed theory, and I wonder if it is perhaps the best practice that love alone just does not always make for good nursing. I find myself arguing that, as a nurse informed and influenced by theory, I "do good nursing". If I were being provocative, I would even go as far as to say that I believe I "do better nursing" than I did before. My curiosity in this instance is that, although these caregivers might not have had theory, they still had heart, and that heart was what the Wright family needed at the moment. Yet, I believe that the Wright family also valued theory; they valued that someone knew about oxygen saturation levels, medication, consolidated lungs, percussion, pain relief, and range-of-motion exercises. I do not think that they would have appreciated errors made because of the lack of knowledge. However, at the end of the day, I wonder which they would need the most, and I offer the belief that theory is good and important, but if theory loses its heart, it means nothing--that practice is still the way that nurses come into nursing. Sometimes, however, we seem to lose our heart in practice, and practice without heart is simply technology, forfeiting the relationship that commands our moral and ethical obligations.

In nursing, we are obligated to be answerable to our profession and to those who we serve because "obligation waits at the door for the philosophers and the genealogists of morals to finish their debates" (Caputo, 1993, p. 192). We are obligated to look at families' lives, not simply to gaze at them in some removed way but to enter into their suffering, joys, deaths, and illnesses to come into amid greet these obligations without turning our backs. Our practices are played out in encounters with suffering, with illness, and yes, sometimes with death. Mrs. Wright's caregivers answered to their obligations with a "coming into" and a "being with" the Wright family. They answered to the obligation with hugs and kisses. They answered with action and practice.

Is the action or verb of nursing always merited in our name? Do we experience the same kind of pride in giving a hug or feeding colored candies to a dying woman as we do in receiving a degree, publishing a paper, or getting a promotion? What do we value? What takes precedence in our profession? How do we as theorists, educators, and practitioners explain that sometimes our theories seem to stand separate from our actions, or that the circulation of knowledge is sometimes unidirectional, or worse, uncommunicative? How do we make sense of the idea that we are even in a place of looking at theory and practice as dichotomous notions? Do our theories ever stand in the way of us being the kind of caregivers that the Wright family experienced? How do we 
understand that Mrs. Wright's caregivers, who are not nurses, and who are closer to practice than to theory, encompass so beautifully the qualities of nursing, which we too, as nurses, would like to sustain? I do not think that we, as nurses, want to claim ownership of these graceful acts of care and love, but I am compelled to ask the following questions: Would a family under my care have the same stories to tell about the way I have nursed them? Would they say that I practiced with my heart as well as with my head?

I have come to believe that the answer to the question, "what is a nurse?" is maybe less important than the answer to the question, "what is nursing?" In some ways, the affiliation to "what is a nurse?"----- to the noun-----implies a loyalty and connection to a profession, whereas valuing the question of "what is nursing" implies the embrace of the practice. I would be proud to be affiliated with those six women who sat at Mrs. Wright's funeral. I believe that they have much to teach me about what the practice of family nursing is really all about-that it is not so much about "being," but "being with" Ultimately, here in the local contingencies of my own life, I am struck with the thought that, if my mother and my family were in need of care (physical, emotional, amid spiritual), hugs, amid nursing, I would hope that we could find the likes of Mrs. Wright's caregivers. I harbor the belief that it also exists in our profession, and that nursing can still be found in nurses.

Nancy J. Moules, RN., MN.

Editorial Assistant

\section{REFERENCES}

Bishop, A. H., \& Scudder, J. R. (1995). Applied science, practice, and intervention technology. In A. Ornery, C. F. Kasper, \& G.G. Page (Eds .), In search of nursing science (pp. 263-274). Thousand Oaks, CA: Sage.

Borgmann, A. (1992). Crossing the postmodern divide. Chicago: University of Chicago Press.

Caputo, J. D. (1993). Against ethics: Contributions to a poetics of obligation with constant reference to deconstruction. Bloomington: Indiana University Press.

Gadamer, H. G. (1989). Truth and method. (2nd rev. ed., J. Weinsheimer \& D.C. Marshall. Trans.). New York: Continuum.

Hoad, T. F. (Ed.). (1986). The concise Oxford dictionary of English etymology. New York: Oxford University Press.

Neufeldt, V., \& Guralnik, D. B. (Eds.). (1988). Webster world dictionary of American English: Third college edition. New York: Simon \& Schuster.

Toulmin, S. (1972). Human understanding: The collective use and evolution of concepts. Princeton. NJ: Princeton University Press. 
Nancy J. Moules, RN, MN., is a doctoral candidate in family systems nursing at the University of Calgary. Her clinical interest is in families experiencing grief and her doctoral research is in the use of therapeutic letters in clinical work with families. She has 20 year's of experience in psychiatric and mental health nursing, and in pediatric oncology, where she was employed as a family support nurse. Publications include (with J.K. Amundson) "Grief-An Invitation to Inertia: A Narrative Approach to Working With Grief" (Journal of Family Nursing. 1997) anti "Legitimizing Grief' Challenging Beliefs That Constrain" (Journal of Family Nursing. 1998). 